\title{
Target for heat capacity consumption that considers safety, energy savings, and comfort: a room heat capacity model using a two- phase difference integration method
}

\author{
Tsuyoshi Kitsuya $^{1} \cdot$ Wei Zang $^{2} \cdot$ Satoshi Kumagai $^{2}$ (D) Shuuzou Kishima $^{3}$
}

Received: 19 July 2016/Accepted: 14 December 2016/Published online: 29 December 2016

(c) The Author(s) 2016. This article is published with open access at Springerlink.com

\begin{abstract}
In this study, the thermal characteristics of an individual room in a building are measured by making use of environmental data. Subsequently, the target heat capacity consumption by the air-conditioning system can be calculated and controlled, depending on the environmental target. By establishing the relationship between a change in the room environment (environmental evaluation index) and the heat capacity consumption of the room (the amount of change of the enthalpy) by the air conditioning, we can calculate the target heat capacity consumption feasible as an environmental target. Relying on an environmental target in calculating the target heat capacity consumption enables setting suitable targets to avert the risk of heat exhaustion or even heatstroke to the residents of the building. In addition, a useful room heat capacity model is suggested that includes a management method using a heat capacity consumption target, with an administration table for evaluating the target.
\end{abstract}

Tsuyoshi Kitsuya

pondax-aoyama@docomo.ne.jp

Wei Zang

zang@ise.aoyama.ac.jp

Satoshi Kumagai

kumagai@ise.aoyama.ac.jp

1 Graduate School of Science and Engineering, Aoyama Gakuin University, Huchinobe 5-10-1, Sagamihara, Kanagawa, Japan

2 Industrial and System Engineering, Aoyama Gakuin University, Huchinobe 5-10-1, Sagamihara, Kanagawa, Japan

3 National Institute for Environmental Studies, Onogawa 16-2, Tsukuba, Ibaraki, Japan
Keywords Building air conditioning · Energy saving · Thermal characteristic . Heat exhaustion - Heatstroke . Indoor comfort

\section{Introduction}

Recently, steps have been taken to limit the amount of energy consumed in office buildings drastically. In addition to energy for lighting and other uses, the air conditioning consumes approximately $40 \%$ of the total electricity used in buildings. A building and energy management system (BEMS) is commonly used to control the air-conditioning systems of office buildings [1-3]. A BEMS is a centralized system that combines management functions relevant to the heat supply and the facility operations. The BEMS mainly carries out the demand control for peak cutting of electric power, as well as monitoring and controlling the entire building or every floor [4-6]. Peak cut control is a function to cut temporarily part of the electric power when electric power use exceeds the contracted amount. Consequently, the BEMS limits the amount of energy consumed. However, as the BEMS does not take into account the conditions and characteristics of any individual room, there is a risk of the room environment deteriorating during the peak cut [7].

Studies have been conducted on efficient air-conditioning control systems, for example, on the optimization of the heat resource operation with thermal load prediction [8-10]. As these studies all aim at the efficient use of the air-conditioning system from the viewpoint of the heat supplier, the thermal characteristics of individual rooms are disregarded. However, a study on the thermal characteristics of the individual room [11] proposed an optimization method to distribute heat to each room. Another study [12] 
proposed utilizing the room-specific thermal inertia for appropriate air-conditioning operations. These studies suggest an appropriate air-conditioning operational method for a predetermined heat quantity. However, a proper evaluation of the predetermined heat quantity (the heat quantity target) was not performed.

In regard of the characteristics of the thermal environment of the room, a study was conducted to estimate the heat loss characteristics of the room using a heat loss coefficient [13]. However, the intention was not to understand the thermal characteristics of the room, which are the overall features of the room environment (temperature, humidity, and $\mathrm{CO}_{2}$ changes) relevant to the heat input of the air conditioning. Moreover, the previous studies did not propose a setting method for the heat quantity target of the air-conditioning system.

In the present study, by understanding the thermal characteristics of the room, we propose a setting method for the heat quantity target of the air conditioning and a setting method to be used by the occupant of the room relevant to the quantity of heat.

\section{Purpose of this study}

Recently, building managers have started implementing energy saving actions in buildings [14, 15]. However, such actions or strategy would probably not include considering the cooling of the building on a room-by-room basis, or a substantial saving of energy. If the air-conditioning requirements were entrusted to the occupants of the individual rooms in a building, the occupants would have the freedom and flexibility to achieve the ambient comfort they preferred. However, such a scenario would be obviously open to abuse of the air-conditioning system that could lead to excessive energy consumption. After the introduction of the electricity regulations of 2011 in Japan, the heat capacity consumption at Aoyama Gakuin University, located in Tokyo was reduced significantly. However, a situation has developed, where the controlling temperatures in the individual rooms were not taken into consideration. Therefore, it has become necessary to establish and manage appropriate consumption targets for room heat capacity to the satisfaction of both the building management and the occupants of the building.

Figure 1 illustrates the plan-do-check-act/adjust (PDCA) cycle to manage the consumption target for room heat capacity that can be effectively employed by a building manager. In this PDCA cycle, the building manager initially assigns the heat capacity consumption target to each room based on the monthly target. Accordingly, each room runs the air-conditioning system based on a given target.

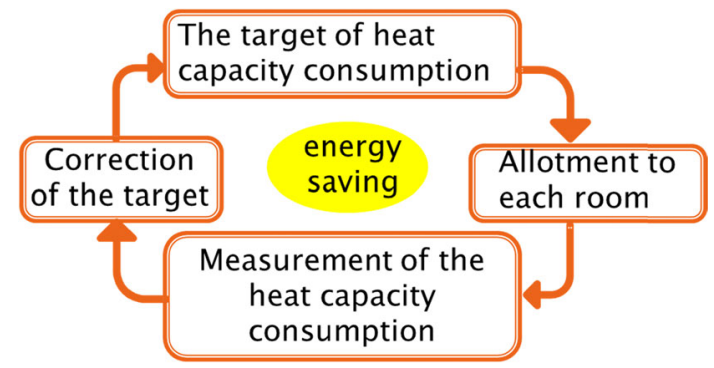

Fig. 1 PDCA cycle for the building manager

Therefore, when the result of heat capacity consumption differs from the expectation, it becomes necessary to modify the heat capacity consumption target to avoid excessive heat consumption or heat stroke risk. Figure 1 represents the means by which a target for room heat capacity can be set and modified.

In view of the above, the aim of this study is to suggest a calculation and management method for a consumption target for room heat capacity that takes into consideration safety, energy saving, and comfort.

It is necessary to measure thermal responses to identify room characteristic to set a target for heat consumption. To achieve the desired energy saving, safety, and comfort, target setting has to be done weekly and monthly. As the setting method is flexible enough to change the target in the middle of month, the occupants are able to conduct energy saving activities in a reasonable manner.

When it becomes difficult to achieve the weekly target owing to unexpected heat consumption, the weekly heat consumption target is corrected downward for the subsequent weeks. The purpose is to achieve the target of heat consumption without exposing the occupants to the risk of heat stroke. In this instance, the room occupant is expected to limit the use of the air conditioner in the subsequent weeks.

However, when it becomes clear that heatstroke risk cannot be avoided, the target for the subsequent weeks will be corrected upward.

\section{Room capacity heat model using a two-phase difference integration method}

Figure 4 demonstrates a procedure to formulate the consumption target of the heat capacity of a room, depending on an environmental target. By establishing the relationship between a change in the room environment and the heat capacity consumption by the air-conditioning system, the consumption target of the heat capacity of the rooms can be formulated as an environmental goal. The WetBulb Globe Temperature (WBGT) is an industrial standard used in Japan to evaluate the indoor environment [16, 17]. This standard was used also in our calculations. WBGT is an 
index that adopts three major factors (humidity, radiant heat, and temperature) that influence the heat balance of a human body. In this way, using WBGT, the risk of exposing a room occupant to excessive heat can be expressed. The calculation methods for WBGT differ depending on the variables, such as the influence of sunlight, which cannot be ignored outdoors but does not need to be taken into consideration indoors. In this study, the influence of sunlight was disregarded in the calculation method of WBGT. The environmental data were measured with a BACSPot device (Fig. 2) installed in the room. The measurements were conducted for one month, namely, from 1-31 August 2015. The environmental data measured by the BACSPot instrument are available online (see Fig. 3).

The following section expands on the calculation methods of the consumption target for the heat capacity of a room, as outlined in Fig. 4.

We compared the data for three years (August 2013, August 2014, and August 2015), which were almost the same for all the dates. Therefore, we used data for 1 month only (August 2015).

\section{Procedure 1. Analysis of the heat capacity consumption of a room using a two-phase difference integration method}

Using an enthalpy (heat capacity) graph, it is possible to calculate the heat capacity consumption of a room and populate the information on a graph. Heat capacity consumption is calculated using a difference integration method, which is an integral calculus method to calculate the differences on a graph. It is, therefore, possible to visualize the change in enthalpy from the graph, as shown in Fig. 5.

It is clear from this figure that the enthalpy decreases when the air conditioning is operated, and the enthalpy

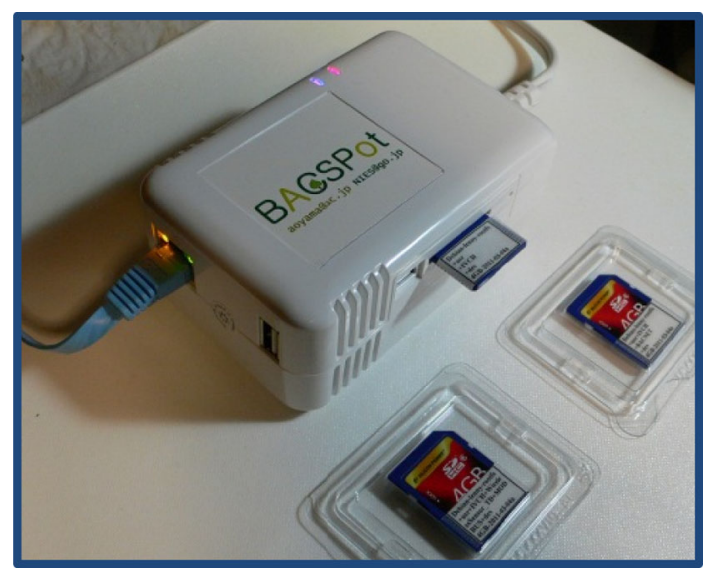

Fig. 2 BACSPot measuring device

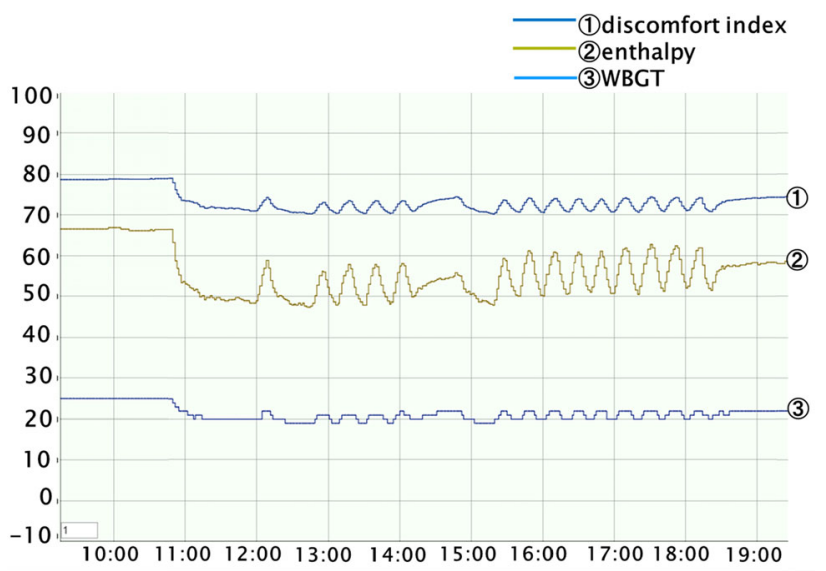

Fig. 3 Environmental data measured by the BACSPot device

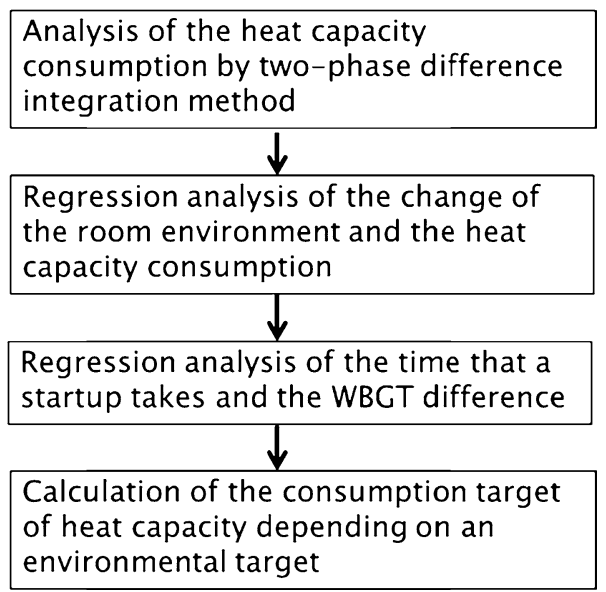

Fig. 4 Calculation procedure

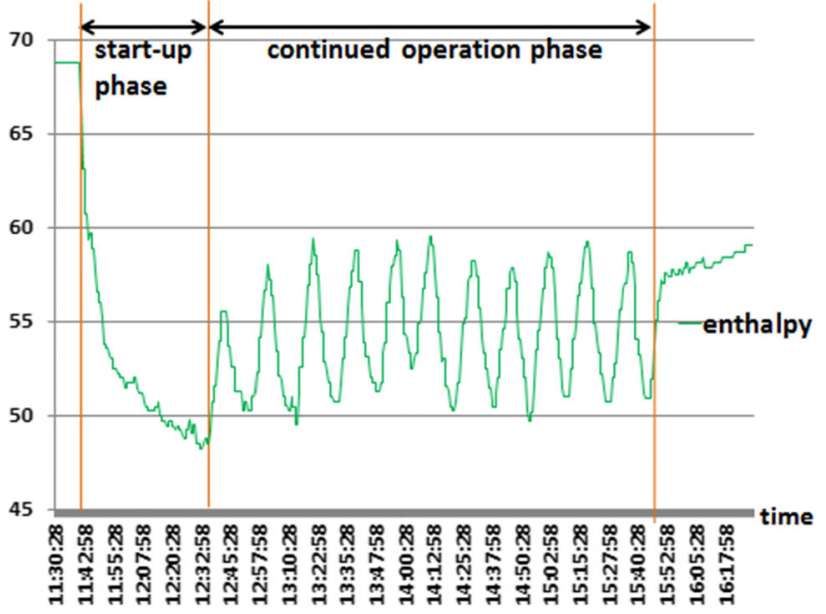

Fig. 5 Enthalpy graph

increases when the air conditioning is switched off. In other words, the quantity of enthalpy decreases when the air conditioning is in operation. This decrease equals the heat capacity consumption for $1 \mathrm{~kg}$ of the air. Therefore, the 
heat capacity consumption of an entire room can be calculated by measuring the weight of the air of the entire room. In addition, the following two phases derive from the differences evident in the graph, namely, a start-up phase and a continued operation phase. The calculations of heat capacity consumption of the two phases were performed daily during the study period.

The weight of the air in a room of $1 \mathrm{~m}^{3}$ was measured and calculated as approximately $1.16 \mathrm{~kg}$. Accordingly, the weight of the air in a room with a volume of $117 \mathrm{~m}^{3}$ was determined as $136 \mathrm{~kg}$.

\section{Procedure 2. Regression analysis of the change} in the room environment (the amount of change in the index of the room environment evaluation) and the heat capacity consumption by the airconditioning operation

The WBGT difference means the differences between WBGT at the time of starting the air conditioning and the average of the peak WBGT wave pattern (see Fig. 6).

The WBGT difference was calculated for each day of the study period, and regression analysis was performed of the WBGT difference and the room heat capacity consumption. The equation of regression of the heat capacity consumption of the room and the WBGT difference were calculated for both the start-up phase and the continued operation phase. Figure 7 shows a scatter diagram of the heat capacity consumption per hour in the start-up phase and the WBGT difference. Figure 8 shows a scatter diagram of the heat capacity consumption per hour relevant to the continued operation phase and the WBGT difference.

From the diagram in Fig. 7, the following equation is derived:

$u_{\mathrm{su}, \mathrm{ps}}=-0.75 W_{\mathrm{s}-\mathrm{p}}+3.359$

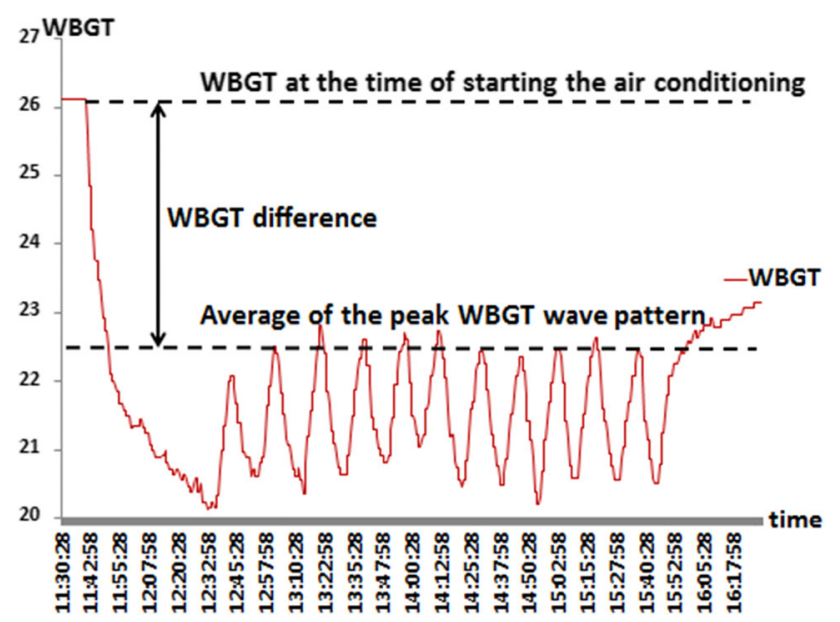

Fig. 6 WBGT graph and WBGT difference

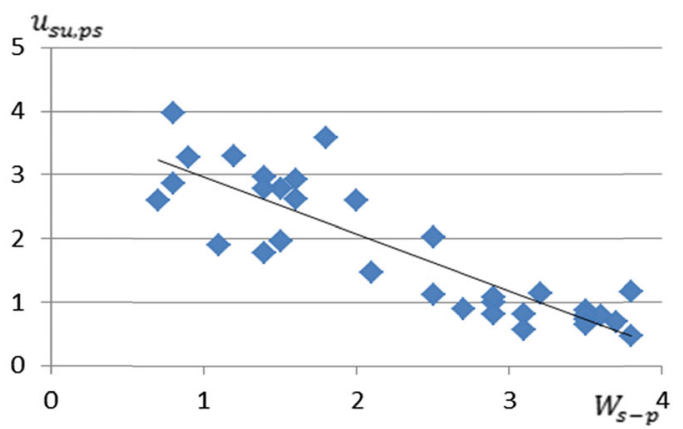

Fig. 7 Scatter diagram of the heat capacity consumption of the room in the start-up phase and the WBGT difference

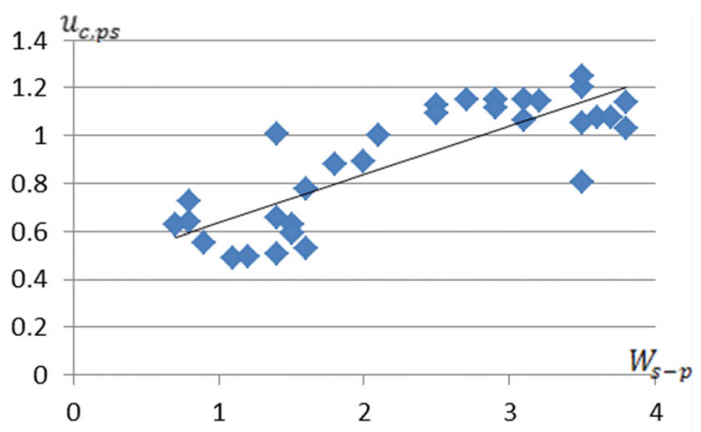

Fig. 8 Scatter diagram of the heat capacity consumption of the room in the continued operation phase and the WBGT difference

where $u_{\text {su,ps }}$ is the heat capacity consumption per time of the start-up phase and $W_{\mathrm{s}-\mathrm{p}}$ is the WBGT difference.

From the diagram in Fig. 8, the following equation is derived:

$u_{c, \mathrm{ps}}=0.15 W_{\mathrm{s}-\mathrm{p}}+0.6528$

where $u_{c, \mathrm{ps}}$ is the heat capacity consumption per time of the continued operation phase.

\section{Procedure 3. Regression analysis of the required time for start-up and the WBGT difference}

The time required for air-conditioning start-up varies according to the thermal characteristics of the room. To determine the time required for start-up, the regression equation of the time required for start-up and the WBGT difference were calculated. Figure 9 shows a scatter diagram of the time required for start-up and the WBGT difference.

From the diagram in Fig. 9, the following equation is derived:

$T_{\mathrm{su}}=1062 W_{\mathrm{s}-\mathrm{p}}-382.44$

where $T_{\mathrm{su}}$ is the time required for start-up. 


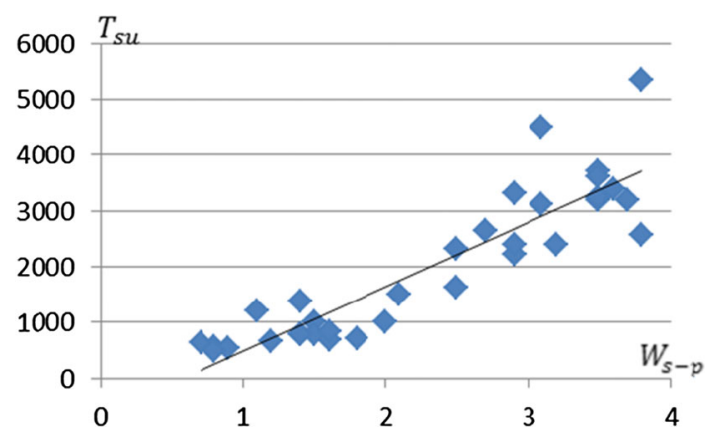

Fig. 9 Scatter diagram of the time required for start-up and the WBGT difference

\section{Procedure 4. Calculation of the consumption target of heat capacity depending on an environmental target}

Using the regression equation established in procedures 2 and 3 , the heat capacity consumption of the start-up phase and the continued operation phase could be estimated.

- Predictive quantity of the heat capacity consumption of the room of the start-up phase:

$u_{\mathrm{su}}=u_{\mathrm{su}, \mathrm{ps}} \times T_{\mathrm{su}}$

where $u_{\mathrm{su}}$ is the heat capacity consumption of the startup phase and $T_{\mathrm{su}}$ is the time required for the start-up.

- Predictive quantity of the heat capacity consumption of the room of the continued operation phase:

$u_{c}=u_{c, \mathrm{ps}} \times\left\{\left(t_{\mathrm{e}}-t_{\mathrm{s}}\right)-T_{\mathrm{su}}\right\}$

where $u_{c}$ is the heat capacity consumption of the continued operation phase, $u_{c, \mathrm{ps}}$ is the heat capacity consumption per time of the continued operation phase, $t_{\mathrm{s}}$ is the air-conditioning starting time, and $t_{\mathrm{e}}$ is the airconditioning finishing time.

The WBGT difference (i.e., $W_{\text {s-p }}$ ) indicates the differences between the WBGT at the time of starting the air conditioning and the average of the peak WBGT wave pattern (see Fig. 6).

Therefore, $W_{\mathrm{s}-\mathrm{p}}$ is expressed by the following equation:

$W_{\text {s-p }}=W_{\text {start }}-W_{\text {peak }}$

where

$W_{\text {start }}$ is the WBGT at the time of starting the air conditioning and $W_{\text {peak }}$ is the average of the peak WBGT wave pattern.

In (6), $W_{\text {peak }}$ can be set as the upper limit level of WBGT and $W_{\text {start }}$ can be predicted from the weather conditions and similar factors. Accordingly, it is possible to calculate $W_{\mathrm{s}-\mathrm{p}}$ :
Substituting $W_{\text {s-p }}$ in (1), $U_{\text {su.ps }}$ can be calculated.

Substituting $W_{\text {s-p }}$ in (2), $U_{c, \text { ps }}$ can be calculated.

Substituting $W_{\mathrm{s}-\mathrm{p}}$ in (3), $T_{\mathrm{su}}$ can be calculated.

Substituting $U_{\text {su,ps }}$ and $T_{\text {su }}$ in (4), $U_{\text {su }}$ can be calculated.

Substituting $U_{c, \text { ps }}$ and $T_{\text {su }}$ in (5), $U_{c}$ can be calculated.

The heat capacity consumption target can be calculated by $U_{\text {su }}$ and $U_{c}$.

Therefore, the heat capacity consumption target can be calculated by the upper limit level of WBGT.

Accordingly, from the predicted quantity of the heat capacity consumption of the room of the start-up phase and the continued operation phase, the daily heat capacity consumption target can be determined. Once the daily heat capacity consumption target is determined, it can be used to calculate weekly or monthly heat capacity consumption targets.

- The heat capacity consumption target:

$Q=|D| \times\left(u_{\mathrm{su}}+u_{c}\right)$

where $Q$ is the heat capacity consumption of the startup phase and the continued operation phase and $|D|$ is the number of days.

\section{The administration table of targets and results of the heat capacity consumption}

\section{Calculation of the consumption target of the heat capacity of a room}

Using actual measurements, the consumption target of the heat capacity for 1 week, corresponding to the environmental target, was determined. To avoid the risk of exposing the occupants to excessive heat, the upper limit level of WBGT was set at $27{ }^{\circ} \mathrm{C}$ and the lower level at WBGT $24{ }^{\circ} \mathrm{C}$.

The following assumptions were made:

- operating time 9:00 am-7:00 pm;

- planning period 5 days;

- WBGT default $28^{\circ} \mathrm{C}$;

- upper limit levels of WBGT 24 and $27^{\circ} \mathrm{C}$.

The consumption target of heat capacity, with an upper limit level of WBGT at $24-27^{\circ} \mathrm{C}$, can be calculated as follows:

- To express the predictive quantity of the heat capacity consumption of the start-up phase, the expressions in Eqs. 1, 3, and 4 are used:

$$
\begin{aligned}
& u_{\mathrm{su}}=u_{\mathrm{su}, \mathrm{ps}} \times T_{\mathrm{su}} \\
& u_{s u}=\left(-0.73 W_{s-p}+3.359\right) \times\left(1062 W_{s-p}-382.44\right) .
\end{aligned}
$$

- To express the predictive quantity of the heat capacity consumption of the continued operation phase, the 
expressions in Eqs. 2, 3, and 5 are used:

$$
\begin{aligned}
u_{c}= & u_{c, \mathrm{ps}} \times\left\{\left(t_{\mathrm{e}}-t_{\mathrm{s}}\right)-T_{\mathrm{su}}\right\} \\
u_{c}= & \left(0.15 W_{\mathrm{s}-p}+0.6528\right) \\
& \times\left\{\left(t_{\mathrm{e}}-t_{\mathrm{s}}\right)-\left(1062 W_{\mathrm{s}-\mathrm{p}}-382.44\right)\right\} .
\end{aligned}
$$

- The weekly heat capacity consumption target, using the expression of Eq. 7:

$$
\begin{aligned}
& Q=|D| \times\left(u_{\mathrm{su}}+u_{c}\right) \\
& Q=-3115\left(28-W_{\mathrm{p}}\right)^{2}+43384\left(28-W_{\mathrm{p}}\right)+112268 \\
& W_{p}=24: Q=214403[\mathrm{~kJ}] \\
& W_{\mathrm{p}}=27: Q=152537[\mathrm{~kJ}]
\end{aligned}
$$

where $W_{\mathrm{p}}$ is the upper limit level of WBGT.

\section{Assumptions about the conventional heat consumption}

To compare the conventional consumption target of heat capacity with the consumption target of heat capacity corresponding to the environmental target, a conventional consumption target of the room heat capacity is assumed. The conventional consumption target of the heat capacity of a room for 1 week can be expressed as follows:

$Q_{y}^{c}=\left(Q_{m}^{c}-U_{y-1}\right) /(K-y+1)$

where $Q_{y}^{c}$ is the conventional consumption target of heat capacity for 1 week, $Q_{m}^{c}$ is the target of heat capacity consumption for a month, $y$ is the periods number, $U_{y-1}$ is the result of heat capacity consumption, and $K$ is the number of periods.

Accordingly, the conventional heat capacity consumption target for a month is determined from the weekly heat capacity consumption target when the upper limit level of WBGT is $24{ }^{\circ} \mathrm{C}$, as outlined in "Calculation of the consumption target of the heat capacity of a room". The following equation can be used to arrive at the conventional heat capacity consumption target of the second week, using the expression of Eq. 8:

$Q_{2}^{c}=\left(857612-U_{1}\right) / 3$.

\section{The administration table of targets and results of heat capacity consumption}

As illustrated in Fig. 10, the conventional heat capacity consumption target of the second week can be expressed as a conventional planning line, using Eq. 9. Figure 10 expresses the target of heat capacity consumption of the

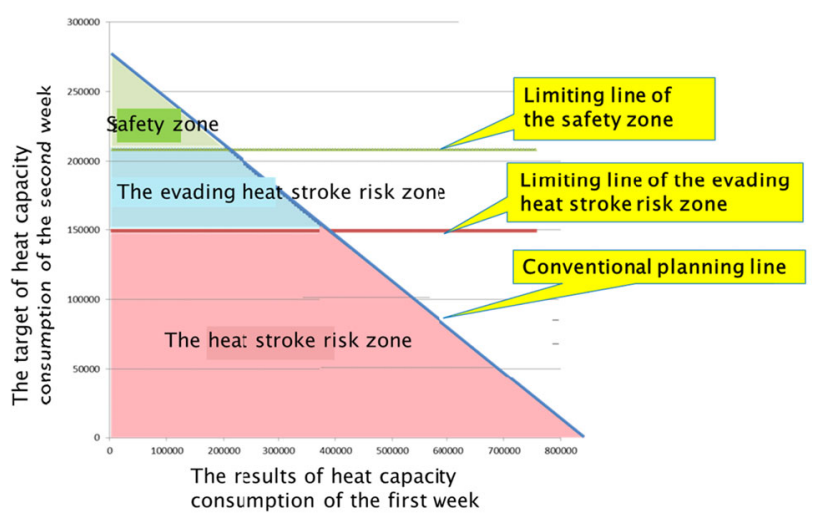

Fig. 10 Administration table of targets and results of heat capacity consumption

second week on the vertical axis and the results of the heat capacity consumption of the first week on the horizontal axis. In other words, Fig. 10 expresses the relationship between the target of the second week and the result of the first week.

Figure 10 presents the details of the weekly heat capacity consumption target when the upper limit level of WBGT is $24^{\circ} \mathrm{C}$, as outlined in "Calculation of the consumption target of the heat capacity of a room", as a limiting line of the safety zone on the graph. Similarly, the weekly heat capacity consumption target is indicated when the upper limit level of WBGT is $27{ }^{\circ} \mathrm{C}$, as a limiting line for evading the heat exposure risk zone on the graph.

From Fig. 10, we can determine whether the target of heat capacity consumption of the second week satisfies an environmental target.

For example, a target of heat capacity consumption of the second week is assumed in the safety zone on the graph in Fig. 11. This figure expresses the surplus of the heat capacity to evade the heatstroke risk zone of the target of heat capacity consumption of the second week. In addition,

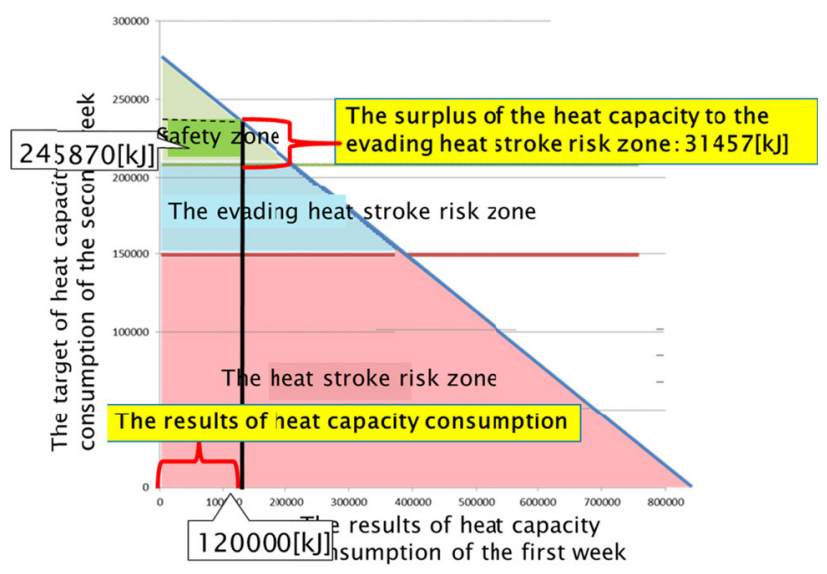

Fig. 11 Example 1 


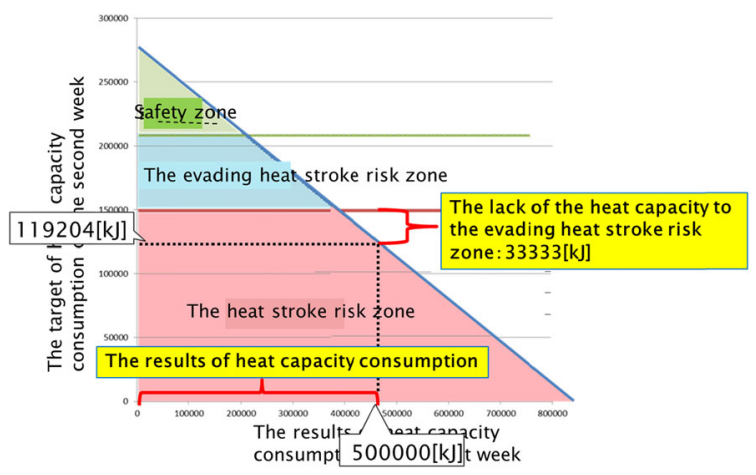

Fig. 12 Example 2

Fig. 11 shows that the target of heat capacity consumption of the second week satisfies an environmental target when the upper limit level of WBGT is $27^{\circ} \mathrm{C}$. The factor in the surplus heat capacity to evade the heatstroke risk zone is believed to be attributable to the room occupant refraining from using the air conditioning for energy saving purposes. Additional factors could be the lower than assumed heat load of the room because of the influence of the outdoor temperature or the number of people in the room.

As another example, it is assumed that the target of heat capacity consumption of the second week does fall within the heatstroke crisis zone of the graph in Fig. 12.

Figure 12 illustrates the lack of the heat capacity to evade the heatstroke risk zone of the target of heat capacity consumption of the second week. This indicates that a correction in the target of heat capacity consumption is necessary. This method illustrates that the administration table of targets and results of heat capacity consumption are useful in determining whether the target of heat capacity consumption is appropriate. In addition, it is useful in setting a target of heat capacity consumption to prevent the risk of heatstroke to the building inhabitants.

\section{Conclusion}

The method for setting the heat capacity consumption target enables setting this target relevant to the thermal response characteristic of the room. In addition, the method takes into consideration safety, energy saving, and comfort factors.

Using this administration table enables modifying the weekly heat capacity consumption target to suit an instance of unexpected heat consumption. Therefore, the room occupant is able to conduct energy saving activities in a reasonable manner. In an instance of unexpected heat consumption, the occupant could still achieve the monthly heat capacity consumption target as long as heat stroke risk is avoided.
In addition, using this administration table of targets and results enables determining whether modification of the monthly heat capacity consumption target is necessary. Accordingly, the room occupant could conduct energy saving activities while evading the risk of heatstroke.

This study presents a method to measure the thermal characteristics of a room for environmental measurement data. This method enables calculating and controlling the target of heat capacity consumption in air conditioning, depending on the environmental target. This suggested management method, together with the administration table of targets, and results of heat capacity consumption were used to establish the usefulness of the room heat capacity model using a two-phase difference integration method.

\section{Future work}

In this study, we used the WBGT as an environmental evaluation index to determine the target heat capacity consumption, as we consider it important to prevent exposing occupants to excessive heat. The intention in the future is to calculate the target heat capacity consumption using other evaluation indices, in which the graph behavior is the same as that of an enthalpy graph. As an example, the discomfort index is used as an important factor relevant to the comfort evaluation of the room.

Open Access This article is distributed under the terms of the Creative Commons Attribution 4.0 International License (http://creative commons.org/licenses/by/4.0/), which permits unrestricted use, distribution, and reproduction in any medium, provided you give appropriate credit to the original author(s) and the source, provide a link to the Creative Commons license, and indicate if changes were made.

\section{References}

1. Tazaki, S.: An overview of building control technology. Kuki Chowa Eisei Kogaku 86(1), 135-141 (2008)

2. Ikeda, K.: The new trend of network and system architecture in the BAS. J. Inst. Electr. Install. Eng. Jpn. 23(9), 655-660 (2003)

3. Sekine, M.: Building automation system in a multi-vender environment. J. Inst. Electr. Install. Eng. Jpn. 23(9), 661-664 (2003)

4. Nakamura, M.: Building and energy management systems in the building automation system. J. Inst. Electr. Install. Eng. Jpn. 23(9), 672-677 (2003)

5. Yoshida, H.: Energy management techniques that the small and medium-sized building targeted. Kuki Chowa Eisei Kogaku 86(1), 1-2 (2012)

6. Shimoda, Y., Yamaguchi, Y., Nishiyama, M., Nishibata, K.: Understanding of characteristics of small and medium size office buildings. Kuki Chowa Eisei Kogaku 86(1), 3-8 (2012)

7. Kumagai, S., Nakano, W., Kishima, S.: Heat resource allocation algorism for client driven air conditioning in building energy 
management: formulation by $0-1$ integer programming. IEEJ Trans. IA. 134(5), 505-516 (2014)

8. Nakamura, Y., Kuriyama, K., Yamamoto, M., Asano, Y.: Optimum control of heating and cooling plant with thermal storage tanks. Kuki Chowa Eisei Kogaku 90(2), 121-131 (2003)

9. Ymaguchi, H., Yoshida, H.: Development of optimum operation schemes for HVAC systems with a thermal storage tank consideration the dehumidification performance. Kuki Chowa Eisei Kogaku 159(1), 19-25 (2010)

10. Yamaguchi, H., Yoshida, H., Matsushita, N., Kimura, H.: Verification of optimum operation method by simulation for the HVAC system with a thermal storage tank in an actual building. Kuki Chowa Eisei Kogaku 167(5), 21-29 (2011)

11. Aizawa, R., Kumagai, S., Kishima, S.: Operation plan of air conditioning by saving and relocating heat resource to the virtual heat resource storage: estimation of room's heat inertia and heat resource allocation algorithm. IEEJ Trans. Electron. Inf. Syst. 136(2), 233-243 (2015)

12. Kumagai, S., Kishima, S.: Building air conditioning model using the room-specific thermal inertia and its implementation as a controller: control method with the learning mechanism of thermal inertia in the building air conditioning. IEEJ Trans. Electron. Inf. Syst. 134(5), 620-633 (2013)

13. Fukai, K., Ichikawa, N.: Study on thermal characteristics of residential room (part 1): simple estimation of natural room temperature with solar heat gain through windows. Academic Lecture Synopsis Collection 2012. Architectural Institute of Japan, 17-18 (2012)

14. Yoshida, Y., Hujinuma, Y., Iguchi, S.: VAV control for energy saving by the mathematics plan type model prediction control technique. Environ. Syst. Pap. Archit. Inst. Jpn. 75(651), 455-464 (2010)

15. Yamaguchi, H., Yoshida, N., and Iguchi, S.: The most suitable driving method of a predictive error of the heat load and the heat storage air-conditioning system, which considered driving in the daytime. Research Report Collection of Kinki branch of the Architectural Institute of Japan. Environment-related 41, 353-356 (2001)

16. Tanabe, S.: Evaluation of thermal comfort. J. Phys. Soc. Jpn. 54(6), 440-448 (1999)

17. Tachikawa, T., Nishi, H.: Method of estimating the number of people using the environment sensor. Kuki Chowa Eisei Kogaku 79(1), 69-75 (2005) 